\title{
The fear of urban sprawl through autonomous vehicles in commuting - a segmentation analysis of the Swiss population*
}

\author{
Raphael Hoerler, Thomas Trachsel and Andrea Del Duce
}

\begin{abstract}
Autonomous vehicles are believed to change the way we will perceive travel time as the car would no longer be driven by a person, enabling other activities to be performed during the time normally used for controlling the vehicle. Especially for private car commuting, scholars suggest that the value of travel time would decrease substantially due to the possibility to work during the car ride. Travel distance might increase in return, as time used during commuting will not be perceived as time lost. This could lead to the preference of living in rural areas, where land prices and rents are typically lower, and, ultimately, to urban sprawl. By looking at the jobs and mobility characteristics of the Swiss population, we argue that only a small percentage of the total population would actually benefit from active use of travel time during commuting, taking away the fear of urban sprawl through automated vehicles.
\end{abstract}

\section{INTRODUCTION}

Through the emergence of the digital age, automated driving is no longer a dream. Many countries around the world already adopted fully automated vehicles (AVs) in test tracks, or already integrated these into the public transport network (e.g. [1]). But also private car manufacturers equip their cars with automated features. Tesla, for example, includes automated lane shifting, lane tracking and automated breaking, to name a few [2]. Moreover, the distributed communication amongst automated vehicles is expected to increase efficiency in road transport and make traffic more fluid (reducing congestion and emissions) as well as safer, since fewer errors are expected in comparison to human driving [3]. Also, considering that the car fleet necessary to satisfy travel demand could be reduced substantially within a sharing-based mobility model, with estimates ranging between $46 \%$ to $91 \%$ in vehicle fleet reduction [4], many stakeholders and scholars emphasize the importance of a shared automated taxi fleet instead of private ownership [5], [6]. Stoiber et al. [7] for example, showed that the Swiss population would be open towards a shared and automated taxi fleet. Despite these anticipated positive effects, researchers also stress the importance to investigate potential negative rebound effects. With increased comfort through higher accessibility [8], enhanced entertainment [9] and reduced costs [10] demand could rise, increasing congestion and emissions again. Another potential rebound effect recognized by research is urban sprawl. Urban sprawl may be induced by a low value of travel time during commuting within a fully automated car with no driver, since travel time would not be perceived as time lost anymore. This may lead to a higher acceptance of longer travel distances and, ultimately, a preference for low density residential choices where typically housing costs are lower.

*Research supported by The Federal Swiss Roads Office through the project "Auswirkungen des automatisierten Fahrens"

R. Hoerler is with the Zurich University of Applied Sciences, 8400 Winterthur, Switzerland, raphael.hoerler@zhaw.ch
However, with ongoing population growth, densification is an important measure to counteract uncontrolled consumption of green spaces, which not only endangers the natural habitat [11] but also quality of life [12]. Urban sprawl would also lead to increased infrastructure costs as, for example, a longer and more dispersed sewer network would be needed [13]. Despite the very current topic and knowledge about potential rebound effects from $\mathrm{AVs}$, few studies considered the actual percentage of the population who could benefit from the active use of travel time during commuting and, as such, represent a potential contributor to urban sprawl. To close this gap, we estimated the percent of the Swiss population who could make use of travel time during the commute by a two-step cluster analysis. The data used for this study stems from the Mobility and Transport Microcensus (MTMC), a nation-wide travel survey conducted every five years [14].

\section{BACKGROUND}

\section{A. Potential drivers of urban sprawl through AVs}

Different factors could have an influence on increased urban sprawl due to the diffusion of AVs. First and foremost, many scholars suggest that vehicle occupants could spend travel time for other activities than driving, reducing costs of travel and congestion [15]. Gelauff et al. [16] for example apply a $20 \%$ reduction in value of travel time for trips longer than five kilometers in their spatial equilibrium model, suggesting a potential increase in urban sprawl from Dutch cities. Meyer et al. 2017 argue that a jump in accessibility through AVs could favor urban sprawl [8]. Contrary, [17] argues that shared fully autonomous vehicles will not lead to urban sprawl as city centers get more attractive with low waiting times for the service, attracting senior households to move closer to the city center. In addition, younger households would not move into rural areas because of the high waiting times of the service and lack of quality education [17]. Similarly, Milakis et al. [18] summarized the views of international accessibility experts into three distinctive views, where one group of experts expect a densification due to lower car ownership, resulting in less parking demand in cities. However, the same experts also recognize the possibility of further suburbanization of cities. Another group of experts expects a relocation to outer areas, whereas the last group of experts do not have a clear view on land use changes.

T. Trachsel is with the Zurich University of Applied Sciences, 8400 Winterthur, Switzerland, thomas.trachsel@zhaw.ch

A. Del Duce is with the Zurich University of Applied Sciences, 8400 Winterthur, Switzerland, andrea.delduce@zhaw.ch 


\section{B. Active use of travel time - for whom?}

Only a very limited number of studies investigated the population, which could benefit from the active use of travel time during commuting. Yet this is important in the discussion about potential unwanted effects like urban sprawl since only if the tasks done during the commute substitute tasks one would have to do anyway, such as sleeping or working, one would accept longer commuting times [19]. Correia et al. [20] further show through a stated choice experiment that the value of travel time within an AV would only be lower for commuting activities as compared to conventional vehicles with a driver, finding no effect for leisure activities. While this experiment stresses the importance to specifically investigate potential urban sprawl through a lower value of travel time in commuting, the results do not tell which percentage of the population would be affected. In this context, it should also be noted that not all jobs require tasks that can be done in a car (e.g. working on a laptop or reading). A distinction of user types is therefore necessary to understand the share of population which may really make an active use of time while traveling in an automated vehicle.

Finally, several studies show that car sickness may affect a large part of users who want to perform activities like reading, working on a computer or watching a movie [21]-[24]. Hence, for a majority of users, doing some key working activities will only be possible on selected road types like highways where the driving dynamics is smoother and less likely to trigger car sickness.

\section{Methodology}

Building on the observations presented in Section II, we define following research questions:

- R1: Are there different groups with regard to their suitability to work during commuting?

- R2: How do the groups differ concerning socioeconomic characteristics and mobility behavior?

- R3: What percent of the Swiss car commuters could benefit from active use of travel time during commuting within an AV?

In order to answer these questions we analyzed data from the MTMC. The MTMC is the most sophisticated transportrelated survey in this regard. More than 57'000 participants, randomly drawn from the Swiss population, are asked about common socio-demographic characteristics and mobility behavior. In addition, origin-destination data is gathered for whole trips and trip legs, allowing very distinct analysis of travel characteristics. Particularly, each trip leg is categorized by road type, i.e. whether the road is a highway, major road or more locally connecting roads. The survey has been conducted by the Swiss Federal Statistical Office (FSO) and the Swiss Federal Office for Spatial Development (ARE) since 1974 and takes place every five years. The newest MTMC is from 2015.

We applied a data driven approach to cluster the Swiss population using the two-step procedure implemented within SPSS Statistics version 26. The two-step approach combines the advantages of both, hierarchical and k-means clustering methods, yielding better balanced groups and is especially suitable for large data like the MTMC [25]. Another asset of the two-step approach refers to the optimal number of clusters being defined by the algorithm instead of heuristic decisions by the user, eliminating potential estimation bias.

Based on the literature about active use of travel time and associated difficulties due to car sickness and assuming, therefore, that driving on highways or major roads would be a prerogative for a comfortable use of travel time for working tasks, we defined the following three variables as input parameters for the two-step cluster algorithm:

- Average kilometer driven on highways

- Average kilometer driven on other major roads

- Age

Age was chosen to include variability in socio-economic characteristics of the groups. In order to assess the suitability of each group to use travel time for working tasks, we considered the following four parameter:

- The share of the group within the whole sample

- Share of industry sectors, with working tasks suitable for automated driving

- Share of commuting trips with at least one trip leg on highways or other major roads between countryside and city/agglomeration (as the smaller streets could lead to travel sickness)

- Percentage of people living in cities or agglomeration

The MTMC summarizes the various professions by the following 10 categories: military service / administration and leadership / scientists / technicians and non-technic professions / office and trade / personal services and sales personnel / agriculture and fishery / craftsmanship and similar jobs / machinery operator and assembly / unskilled labor. During the following analysis, we assume that especially the categories administration and leadership, scientists and office and trade could benefit from the active use of travel time during autonomous commuting, since these comprise occupations which mostly require tasks compatible with an office environment.

Furthermore, we calculate the share of commuting trips with at least one trip leg on highways or other major roads between countryside and city/agglomeration with the following information: the mode used per trip leg (car as a driver and car as a passenger), purpose of the trip leg (whether for working, studying or returning home), trip legs on highways, other major roads, secondary roads and local connecting roads, place of living (city, agglomeration and countryside) and place of work (city, agglomeration and countryside).

In order to assess the quality of the results, we checked the cluster size ratio, silhouette measure for cohesion and separation and the interpretability of the variation within the variables among clusters. Furthermore, we analyzed the change in Akaike's Information Criterion (AIC) for cluster solutions starting from one to fifteen clusters. The cluster solution with the highest ratio of distance measures indicates the best separation without losing interpretability due to too many clusters. As clearly visible within TABLE I, the optimal 
cluster solution would be five, which has been detected by the auto-clustering algorithm of the two-step procedure.

TABLE I. AUTO-CLUSTERING

\begin{tabular}{|l|l|l|l|l|}
\hline $\begin{array}{l}\text { Number } \\
\text { of } \\
\text { Clusters }\end{array}$ & AIC & AIC Change & $\begin{array}{c}\text { Ratio of } \\
\text { AIC } \\
\text { Changes }\end{array}$ & $\begin{array}{c}\text { Ratio of } \\
\text { Distance } \\
\text { Measures }\end{array}$ \\
\hline 1 & 21731.52 & & & \\
\hline 2 & 15310.43 & -6421.09 & 1.00 & 1.71 \\
\hline 3 & 11551.50 & -3758.93 & 0.59 & 1.56 \\
\hline 4 & 9149.50 & -2402.00 & 0.37 & 1.30 \\
\hline 5 & 7309.79 & -1839.71 & 0.29 & 2.27 \\
\hline 6 & 6504.85 & -804.93 & 0.13 & 1.22 \\
\hline 7 & 5846.06 & -658.79 & 0.10 & 1.11 \\
\hline 8 & 5256.44 & -589.63 & 0.09 & 1.31 \\
\hline 9 & 4809.56 & -446.88 & 0.07 & 1.03 \\
\hline 10 & 4374.09 & -435.47 & 0.07 & 1.33 \\
\hline 11 & 4048.47 & -325.61 & 0.05 & 1.14 \\
\hline 12 & 3764.86 & -283.61 & 0.04 & 1.22 \\
\hline 13 & 3533.90 & -230.96 & 0.04 & 1.04 \\
\hline 14 & 3313.21 & -220.69 & 0.03 & 1.40 \\
\hline 15 & 3159.23 & -153.97 & 0.02 & 1.20 \\
\hline & & & & \\
\hline
\end{tabular}

IV. RESULTS

Within this section, we will first describe the segments according to their socio-demographic and mobility-related characteristics. Second, we derive the percent of the population able to work in an AV per segment and of whole Switzerland.

\section{A. Segments}

The two-step cluster algorithm generated five clusters by utilizing the information of age, kilometers driven on highways and kilometers driven on other major roads. In order to be able to analyze the kilometers driven per trip leg, we expanded the cluster membership for each trip leg of the same person (as the MTMC captures all trip legs from the same person within one day). Only the cases with trip legs used for commuting (working, studying and returning home) were used for the remaining of the paper. The cluster solution is shown in Figure 1.

\section{Cluster sizes $\left(\mathrm{n}=21^{\prime} 052\right)$}

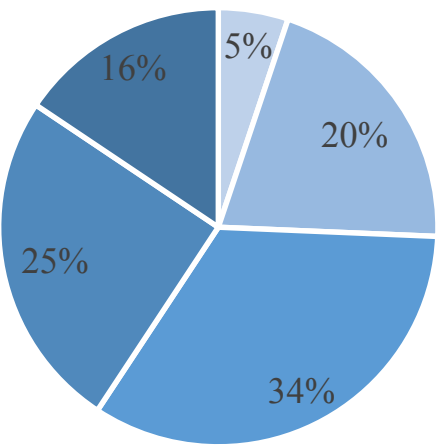

- Cluster 1 - Cluster 2 - Cluster 3 - Cluster 4 - Cluster 5

Figure 1. Percentage of cases within each of the five clusters who use the car for commuting.

The ratio of the largest to the smallest cluster is around 6.5. Yet only cluster 1 is considerably different in size than the other four clusters, remaining with 1084 cases. As the number of cases exceed 1000 we consider the cluster solution as suitable for further analysis. The silhouette measure for cohesion and separation is roughly 0.5 , indicating a medium cluster separation quality. Yet most importantly, the differences within the clusters need to allow meaningful comparisons and naming of the respective groups, which we will address in the subsequent chapter.

TABLE II provides an overview of the characteristics of the three input variables and other variables included in the analysis. This information can be used to describe and characterize the groups in more detail.

TABLE II. MOBILITY BEHAVIOUR AND SOCIO-DEMOGRAPHICS

\begin{tabular}{|l|l|l|l|l|l|}
\hline \multicolumn{1}{|c|}{ Variable } & $\begin{array}{c}\text { Cluster } \\
\mathbf{1}\end{array}$ & $\begin{array}{c}\text { Cluster } \\
\mathbf{2}\end{array}$ & $\begin{array}{c}\text { Cluster } \\
\mathbf{3}\end{array}$ & $\begin{array}{c}\text { Cluster } \\
\mathbf{4}\end{array}$ & $\begin{array}{c}\text { Cluster } \\
\mathbf{5}\end{array}$ \\
\hline $\begin{array}{l}\text { Average number } \\
\text { of km driven on } \\
\text { highways for } \\
\text { commuting per } \\
\text { day }\end{array}$ & 2.7 & 4.6 & 1.5 & 33.4 & 1.7 \\
\hline $\begin{array}{l}\text { Average number } \\
\text { of km driven on } \\
\text { other major roads } \\
\text { for commuting per } \\
\text { day }\end{array}$ & 1.4 & 12.0 & 1.3 & 6.9 & 2.1 \\
\hline $\begin{array}{l}\text { Average number } \\
\text { of km driven on } \\
\text { secondary roads } \\
\text { for commuting per } \\
\text { day }\end{array}$ & 1.9 & 2.1 & 2.4 & 2.7 & 2.4 \\
\hline $\begin{array}{l}\text { Average number } \\
\text { of km driven on } \\
\text { local connecting } \\
\text { roads for } \\
\text { commuting per } \\
\text { day }\end{array}$ & 4.5 & 5.3 & 5.2 & 5.1 & 5.1 \\
\hline $\begin{array}{l}\text { Percentage of trips } \\
\text { with at least one } \\
\text { leg on a highway } \\
\text { or other major road } \\
\text { between }\end{array}$ & $70 \%$ & $96 \%$ & $74 \%$ & $96 \%$ & $72 \%$ \\
\hline & & & & & \\
\hline
\end{tabular}




\begin{tabular}{|l|l|l|l|l|l|}
\hline \multicolumn{1}{|c|}{ Variable } & $\begin{array}{c}\text { Cluster } \\
\mathbf{1}\end{array}$ & $\begin{array}{c}\text { Cluster } \\
\mathbf{2}\end{array}$ & $\begin{array}{c}\text { Cluster } \\
\mathbf{3}\end{array}$ & $\begin{array}{c}\text { Cluster } \\
\mathbf{4}\end{array}$ & $\begin{array}{c}\text { Cluster } \\
\mathbf{5}\end{array}$ \\
\hline $\begin{array}{l}\text { countryside and } \\
\text { city/agglomeration }\end{array}$ & & & & & \\
\hline $\begin{array}{l}\text { Average } \\
\text { commuting time in } \\
\text { min (return) }\end{array}$ & 27.1 & 39.8 & 26.0 & 54.5 & 26.1 \\
\hline Age in years & 65.4 & 49.6 & 48.0 & 37.8 & 21.7 \\
\hline Household size & 2.0 & 2.8 & 3.0 & 2.9 & 3.3 \\
\hline $\begin{array}{l}\text { Percent of the } \\
\text { working categories } \\
\text { suitable for } \\
\text { autonomous } \\
\text { commuting part- }\end{array}$ & $40 \%$ & $43 \%$ & $39 \%$ & $44 \%$ & $25 \%$ \\
\hline $\begin{array}{l}\text { Percent of part workers } \\
\text { time } \\
\text { (without } \\
\text { pensioners) }\end{array}$ & $27 \%$ & $32 \%$ & $20 \%$ & $16 \%$ \\
\hline $\begin{array}{l}\text { Percent woman } \\
\text { Percent living in }\end{array}$ & $85 \%$ & $34 \%$ & $41 \%$ & $33 \%$ & $42 \%$ \\
\hline $\begin{array}{l}\text { cities } \\
\text { agglomeration }\end{array}$ & & $70 \%$ & $74 \%$ & $75 \%$ & $71 \%$ \\
\hline
\end{tabular}

With an average age of just over 65 years, the first group is well above the average age of all groups (43 years). Furthermore, even though the car is the main means of transport, this group covers very small distances for commuting, has the smallest household size and the highest percent of part-time workers (43\%). In summary, we describe this group as the Car-affine seniors.

The second group is on average 50 years old, is mainly commuting by car on other major roads $(\varnothing 12 \mathrm{~km})$ and has an above-average percent of suitable professions for autonomous commuting compared to the other groups (43\%). With regard to other variables, this group is predominantly in the midfield. We call this group the Regional active group.

The third group shows a high proportion of women (41\%), an above-average number of part-time workers and also the lowest average commuting time. The distances travelled on the various road categories are low, but mainly on local connecting roads (Ø $5.2 \mathrm{~km})$. We therefore refer to this group as the Part-time locals.

The fourth group is distinguished from the other groups by the long distances travelled on highways. With a total (return) distance of $33 \mathrm{~km}$ on highways and a further $7 \mathrm{~km}$ on other major roads, people in this group spend up to 55 minutes per day in the car for commuting. The average age of the group is 38 years and $44 \%$ of the members in it have an employment based on office compatible activities. We thus name this group the Convinced car commuters.

In the fifth and last group there are mainly pupils, students and workers from agriculture and construction. Accordingly, the average age of 22 years is significantly lower than the other groups. In addition, this group has the largest household size. This is due to the fact that a large proportion live at their parents' house, and comparing the household size across the various occupational fields reported within the MTMC, people from the construction and agricultural industries generally have a larger household size compared to other occupational fields. Similar to group three, people in this group move mainly on local connecting roads (Ø $5.1 \mathrm{~km})$. In the following, we refer to this group as the Local young drivers.

Figure 2 summarizes the main differences among the five groups in a spider chart. The highest value per group corresponds to $100 \%$, whereby the remaining groups are relative to the highest value amidst groups.

\section{DCar-affin seniors DRegional actives \\ -Part-time locals $\square$ Convinced car commuters \\ DLocal young drivers}

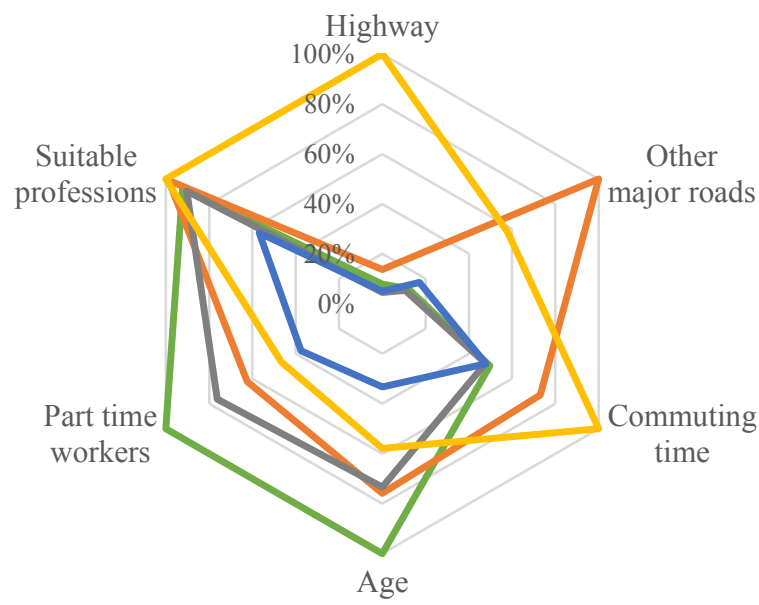

Figure 2. Spider chart with information about highway and other major road use, commuting time, age, part time workers and suitable professions.

\section{B. Percent of the population able to work in an AV per segment}

We see from the above analysis that especially the Regional actives and the Convinced car commuters exhibit characteristics in favor of using the travel time for working tasks, because they have a high average commuting time and long distances on highways and other major roads. To get a better understanding of the order of magnitude of people which may benefit from an active use of time, we calculate the proportion of Swiss people suitable for working while commuting in an autonomous vehicle for each group according to the criteria mentioned in section III. The following calculations assumes a total number of car commuters in Switzerland of 2,156,000 based on available figures from 2016 [26],

Group one, Car-affine seniors: Measured in terms of the proportion of the population who use cars as their main commuting mode, the proportion of Auto-affine seniors is only five percent. Administration and leadership, scientists as well as office and trade make up 40 percent of the professions in group one. This group's car commuting trips between the countryside and the city/agglomeration with at least one leg on a highway or other major road account for 70 percent of all trips. Last, 80 percent are living within the city. As such, the population would correspond to 25,052 persons in Switzerland. 
Group two, Regional actives: The next group accounts for 21 percent of all groups. In comparison to the first group, the sectors in which working during autonomous commuting would be possible is slightly higher (43\%). With 96 percent of commuting trips with at least one trip leg on highways or other major roads between the countryside and the city/agglomeration, this group has a higher potential for working while commuting in an AV. Yet the percent living in the city or agglomeration is slightly smaller (70\%). This group would correspond to 127,764 persons in Switzerland.

Group 3, Part-time locals: Part-time locals are the largest group, accounting for roughly 34 percent of the total sample. Around 39 percent of the occupations would be suitable for work while commuting in an AV. However, the number of trips with at least one leg on highways or other major roads between the countryside and the city/agglomeration account for only 74 percent. Seventy-four percent of the population are living within the city or agglomeration. The total population in Switzerland would account to 155,968 persons.

Group 4, Convinced car commuters: With 25 percent of the total sample, the Convinced car commuters are a larger group. Furthermore, 44 percent of the professions in this group are suitable for automated commuting. In the end, the Convinced car commuter's trips with at least one leg on highways and other major roads between countryside and the city/agglomeration account for 96 percent. Last, 75 percent are living within the city or agglomeration. Therefore, this group would correspond to 169,916 Swiss persons.

Group 5, Local young drivers: The last group, the Local young drivers, make up 16 percent of the total sample and are therefore a smaller group. Only 25 percent of the professions would be suitable for working during the commute. In addition, 72 percent of trips between the countryside and the city/agglomeration are driven with at least one trip leg on highways or other major roads. In comparison to the other groups, a smaller percent of people are living in the city or agglomeration (71\%). Accordingly, this group would represent 42,222 persons in Switzerland.

In light of the above results, the combined population suitable to work in an autonomous vehicle is around 520,921 persons in Switzerland, which is roughly 24 percent of the total population commuting to work by car.

\section{DISCUSSION}

With 24 percent of the total car commuter population suitable to actively use the travel time for work, we see a low risk in increased urban sprawl from autonomous commuting. It is important to consider, in this context, that many different factors influence housing location choices (e.g. family status, availability of leisure activities [27]), the potentials of autonomous commuting being only one further possible element.

Since there is little experience with automated driving yet, we acknowledge the uncertainty in some of the assumptions made. We do not know yet if there will be a major mode shift to autonomous cars from people previously using public transport. However, the general trends and focus of sustainable mobility planners lies in car-free households and strengthening public transport, within a general push for urbanization. Moreover, while there are expectations for AVs to conquer the market in the long-term, the rate is uncertain due to policy aspects and the potentially negative effects of mixed traffic. One further important assumption in the discussion above concerns the professions suitable to work in an AV. Sectors based on office work could increase in the future with further digitalization of the economy. This would mean that, potentially, more people would be involved in jobs requiring activities, which could be done in a moving car. However, when including the share of trips on the highway or major road in the picture and considering that many jobs like service delivery, construction work or maintenance will still be needed in the future, we estimate this effect to remain small. Furthermore, not all people having professions we defined as suitable for working in an AV will exploit this possibility. Similarly, some people from categories defined not suitable may find some tasks suitable to be performed in an AV. All in all, one could expect the overall effect to level out. Another assumption was that only streets without too many curves and uneven surfaces (highways and other major roads) would be suitable to work while commuting due to travel sickness issues. While some ideas to counteract this problem are already in development, see for example [24], it is not known yet how effective and compatible these measures will be with an extensive use in the car. We further assumed that commuting time does not affect the possibility to work within an AV. In reality, however, only a share of working tasks can be done within a limited time range and it is not clear whether or not commuters would start working unless the trip duration exceeds a certain time. The share of trips driven on highways or other major roads between the countryside and the city/agglomeration exceeding five, 10 and 15 minutes are shown in TABLE III. If we introduce the assumption that it would only make sense to start working on trips longer than five, 10 or 15 minutes, the number of trips suitable for working reduces significantly.

TABLE III. CAR TRIPS BETWEEN THE COUNTRYSIDE AND THE CITY/AGGLOMERATION - TIME USE

\begin{tabular}{|l|l|l|l|l|l|l|}
\hline & $\begin{array}{c}\text { Car- } \\
\text { affine } \\
\text { seniors }\end{array}$ & $\begin{array}{c}\text { Regional } \\
\text { actives }\end{array}$ & $\begin{array}{c}\text { Part- } \\
\text { time } \\
\text { locals }\end{array}$ & $\begin{array}{c}\text { Convinced } \\
\text { car } \\
\text { commuters }\end{array}$ & $\begin{array}{c}\text { Local } \\
\text { young } \\
\text { drivers }\end{array}$ & $\begin{array}{c}\text { Total } \\
\text { population } \\
\text { suitable to } \\
\text { work }\end{array}$ \\
\hline $\begin{array}{l}\text { Share of } \\
\text { trips } \\
\text { exceeding } \\
\text { five } \\
\text { minutes }\end{array}$ & $88 \%$ & $93 \%$ & $82 \%$ & $92 \%$ & $83 \%$ & $21 \%$ \\
\hline $\begin{array}{l}\text { Share of } \\
\text { trips } \\
\text { exceeding } \\
10 \\
\text { minutes }\end{array}$ & $82 \%$ & $83 \%$ & $70 \%$ & $86 \%$ & $66 \%$ & $19 \%$ \\
\hline $\begin{array}{l}\text { Share of } \\
\text { trips } \\
\text { exceeding } \\
15 \\
\text { minutes }\end{array}$ & $65 \%$ & $58 \%$ & $52 \%$ & $78 \%$ & $45 \%$ & $15 \%$ \\
\hline
\end{tabular}

We conclude by observing that there seems to be a common agreement that a shared and pooled autonomous fleet would be beneficial over private autonomous vehicles in many aspects [28], [29]. It should be noted, however, that the assumption of a lower value of travel time in AVs should then be made with further care, since the range of suitable working 
tasks or activities might be reduced when sharing the same car with other commuters.

\section{CONCLUSION}

In this paper, we differentiated the Swiss car commuters through a cluster analysis and investigated the suitability of these groups to work in an AV. The aim was to identify what part of the population may use travel time for working purposes and, ultimately, lead to urban sprawl through the acceptance of longer trips. We find that only $24 \%$ of the total car commuters living in the city or agglomeration exhibit characteristics that would allow working tasks during the commute. Taking into account that a multitude of factors are relevant in the decision of living in the countryside or stay within the city or agglomeration, we conclude that a considerably lower fraction of this $24 \%$ of population is likely to choose a housing solution in a sprawled region due to the advantages of automated driving. As such, the danger of urban sprawl due to automated driving is here deemed as small.

The generalizability of these results to other countries needs to be considered with care. Countries like the US, Canada or Germany have a more dispersed and flat road network, lowering the chance of travel sickness and therefore increase the potential for active time use in the car. Specific trip characteristics like duration, length and road types need to be taken into account when evaluating the true potentials of automated driving.

\section{REFERENCES}

[1] 'Media Release: Self-driving bus in regular service for a year'. [Online]. Available: https://www.trapezegroup.eu/news/press-releaseself-driving-bus-in-regular-service-for-a-year. [Accessed: 02-Dec2019].

[2] M. Dikmen and C. M. Burns, 'Autonomous Driving in the Real World: Experiences with Tesla Autopilot and Summon', in Proceedings of the 8th International Conference on Automotive User Interfaces and Interactive Vehicular Applications, New York, NY, USA, 2016, pp. 225-228.

[3] L. M. Hulse, H. Xie, and E. R. Galea, 'Perceptions of autonomous vehicles: Relationships with road users, risk, gender and age', Safety Science, vol. 102, pp. 1-13, Feb. 2018.

[4] A. Soteropoulos, M. Berger, and F. Ciari, 'Impacts of automated vehicles on travel behaviour and land use: an international review of modelling studies', Transport Reviews, vol. 39, no. 1, pp. 29-49, Jan. 2019.

[5] R. Hoerler, F. Haerri, and M. Hoppe, 'New Solutions in Sustainable Commuting - The Attitudes and Experience of European Stakeholders and Experts in Switzerland', Social Sciences, vol. 8, no. 7, p. 220, Jul. 2019.

[6] D. J. Fagnant and K. M. Kockelman, 'The travel and environmental implications of shared autonomous vehicles, using agent-based model scenarios', Transportation Research Part C: Emerging Technologies, vol. 40, pp. 1-13, Mar. 2014

[7] T. Stoiber, I. Schubert, R. Hoerler, and P. Burger, 'Will consumers prefer shared and pooled-use autonomous vehicles? A stated choice experiment with Swiss households', Transportation Research Part D. Transport and Environment, vol. 71, pp. 265-282, Jun. 2019.

[8] J. Meyer, H. Becker, P. M. Bösch, and K. W. Axhausen, 'Autonomous vehicles: The next jump in accessibilities?', Research in Transportation Economics, vol. 62, pp. 80-91, Jun. 2017.

[9] J. Jain and G. Lyons, 'The gift of travel time', Journal of Transport Geography, vol. 16, no. 2, pp. 81-89, Mar. 2008.
[10] R. Abe, 'Introducing autonomous buses and taxis: Quantifying the potential benefits in Japanese transportation systems', Transportation Research Part A: Policy and Practice, vol. 126, pp. 94-113, Aug. 2019

[11] R. I. Mcdonald, P. Kareiva, and R. T. T. Forman, 'The implications of current and future urbanization for global protected areas and biodiversity conservation', Biological Conservation, vol. 141, no. 6, pp. 1695-1703, Jun. 2008.

[12] R. Ewing, R. Pendall, and D. Chen, MEASURING SPRAWL AND ITS IMPACT, vol. 1. 2002.

[13] S. Suter, A. Müller, H. Sommer, and D. Kramer, 'Siedlungsentwicklung und Infrastrukturkosten', ECOPLAN, Bern, Schlussbericht zuhanden des Bundesamtes für Raumentwicklung, des Staatssekretariats für Wirtschaft und des Amtes für Gemeinden und Raumordnung des Kantons Bern, Aug. 2000.

[14] F. O. for S. D. ARE, 'Mobility and Transport Microcensus (MTMC)'. [Online]. Available: https://www.are.admin.ch/are/en/home/verkehrund-infrastruktur/grundlagen-und-daten/verkehrsverhalten.html. [Accessed: 19-Nov-2019].

[15] J. M. Anderson, N. Kalra, K. D. Stanley, P. Sorensen, C. Samaras, and T. A. Oluwatola, 'Autonomous Vehicle Technology: A Guide for Policymakers', Rand Corporation, Santa Monica, Calif, 2016.

[16] G. Gelauff, I. Ossokina, and C. Teulings, 'Spatial and welfare effects of automated driving: Will cities grow, decline or both?', Transportation Research Part A: Policy and Practice, vol. 121, pp. 277-294, Mar. 2019.

[17] W. Zhang, 'The interaction between land use and transportation in the era of shared autonomous vehicles: a simulation model', May 2017.

[18] D. Milakis, M. Kroesen, and B. van Wee, 'Implications of automated vehicles for accessibility and location choices: Evidence from an expert-based experiment', Journal of Transport Geography, vol. 68, pp. $142-148$, Apr. 2018

[19] B. Pudāne, M. Rataj, E. J. E. Molin, N. Mouter, S. van Cranenburgh, and C. G. Chorus, 'How will automated vehicles shape users' daily activities? Insights from focus groups with commuters in the Netherlands', Transportation Research Part D: Transport and Environment, Dec. 2018.

[20] G. H. de A. Correia, E. Looff, S. van Cranenburgh, M. Snelder, and B. van Arem, 'On the impact of vehicle automation on the value of travel time while performing work and leisure activities in a car: Theoretical insights and results from a stated preference survey', Transportation Research Part A: Policy and Practice, vol. 119, pp. 359-382, Jan. 2019

[21] M. Sivak and B. Schoettle, 'MOTION SICKNESS IN SELFDRIVING VEHICLES', The University of Michigan Transportation Research Institute Ann Arbor, Michigan, USA, 2015.

[22] C. Diels, J. E. Bos, K. Hottelart, and P. Reilhac, 'Motion Sickness in Automated Vehicles: The Elephant in the Room', in Road Vehicle Automation 3, G. Meyer and S. Beiker, Eds. Cham: Springer International Publishing, 2016, pp. 121-129.

[23] N. Isu, T. Hasegawa, I. Takeuchi, and A. Morimoto, 'Quantitative analysis of time-course development of motion sickness caused by invehicle video watching', Displays, vol. 35, no. 2, pp. 90-97, Apr. 2014

[24] O. X. Kuiper, J. E. Bos, and C. Diels, 'Looking forward: In-vehicle auxiliary display positioning affects carsickness', Applied Ergonomics, vol. 68, pp. 169-175, Apr. 2018.

[25] A. Tkaczynski, 'Segmentation Using Two-Step Cluster Analysis', in Segmentation in Social Marketing: Process, Methods and Application, T. Dietrich, S. Rundle-Thiele, and K. Kubacki, Eds. Singapore: Springer, 2017, pp. 109-125.

[26] Bundesamt für Statistik (BFS), 'Pendlermobilität in der Schweiz 2016 - Mit einer Vertiefung zu den Pendlerströmen zwischen den Gemeinden | Publikation', Neuchâtel, Aug. 2018.

[27] E. Thomas, I. Serwicka, and P. Swinney, 'Urban demographics Why people live where they do'. Centre for Cities, 2015.

[28] D. J. Fagnant and K. M. Kockelman, 'Dynamic ride-sharing and fleet sizing for a system of shared autonomous vehicles in Austin, Texas', Transportation, vol. 45, no. 1, pp. 143-158, Jan. 2018

[29] W. Zhang, S. Guhathakurta, J. Fang, and G. Zhang, 'Exploring the impact of shared autonomous vehicles on urban parking demand: An agent-based simulation approach', Sustainable Cities and Society, vol. 19 , pp. 34-45, Dec. 2015 